\title{
A Canadian Perspective on a Child's Consent to Research within a Context of Family-Centered Care: From Incompatibility to Synergy
}

\author{
Linda Sheahan ${ }^{1}$, Michael Da Silva ${ }^{2,3}$, Christine Czoli ${ }^{3,4}$ and Randi Zlotnik Shaul ${ }^{3 *}$
}

1 Joint Centre for Bioethics University of Toronto, Toronto, Canada

${ }^{2}$ University of Toronto Faculty of Law, Toronto, Canada

${ }^{3}$ The Hospital for Sick Children, Toronto, Canada

${ }^{4}$ Faculty of Applied Health Sciences, University of Waterloo, Waterloo, Canada

\begin{abstract}
Two major trends have developed in pediatric bioethics: family-centered care and increased recognition of emerging autonomy through legal and policy entrenched rights. The different foci of their corresponding health care delivery models ("family-centered" or "patient-/child-centered") create the potential for conflict in the context of seeking consent to research or, as will be presented, the possibility of integration. Given the state of current bioethical principles and legal holdings, the pediatric patient should ultimately be the primary focus of ethical consideration and, at least in the context of dissenting to research, the child's autonomous wishes should reign. However, in recognizing and supporting a child's emerging autonomy, the family context should also be respected and taken into account. This discussion articulates the values underpinning these two important trends in pediatric health care delivery, and proposes a model for obtaining consent for pediatric research in the current context.
\end{abstract}

\section{Keywords: Child; Consent; Pediatric; Research; Ethics}

\section{Introduction}

The recent development of pediatric bioethics has seen two dominant trends evolve simultaneously: (1) the framework of familycentered care and (2) recognition of the emerging autonomy and rights of children. The former led to the development of a "family-centered" care health care delivery model while the latter is consistent with a "patient-/child-centered" care model. Both health care delivery models are fundamental to caring for children in Canadian hospitals and each model is accordingly increasingly pursued as a vehicle for guiding the delivery of health care in the best interests of children. While these recent trends have resulted in a kind of hybrid model of care on a functional level, they hold an inherent tension in establishing who is the ultimate decision-maker in health related issues? This tension is particularly relevant in obtaining consent for participation in pediatric research.

In the last 25 years, family-centered care has become a familiar component of pediatric clinical practice in North America. While children in early pediatric hospitals were often kept apart from their parents, who had little to no say in the care given to their children, eventually simple moves like allowing mothers to stay with their breastfed infants expanded into a wider recognition of the importance of parents in pediatric health care. The family-centered care movement as we know it today emerged post-World War II and crystallized after the 1970s [1]. Today, many healthcare executives view patients and families as important decision-making partners and many health care institutions include family participants at the executive meeting level [2]. The movement is located in multiple, distinct disciplines. In the academic world, it has been ingrained in children's nursing and therapy curricula in particular [3]. Its bases, however, can also be found in social work. Family-centered care "fits well with social work perspectives that understand individuals in the context of their family system and greater environment [4]. The traditional triad has the parent(s) in the role of substitute decision maker recognizing that the parent is in the best position to be able to appreciate what is in the child's best interests. The language of family - centered care while intended as a vehicle for bringing benefit to the child, at least in language, considers the interests of those beyond the triad-focused patient.

Along with the rise of family-centered care, pediatric bioethics has also seen the rise of a framework that emphasizes the development of children's autonomy and rights. This model of health care focused on the unique needs and wishes of the patient is often referred to as "patient-centered". In a pediatric context this same philosophy is often referred to as "child-centered". Pediatric clinical research now requires recognition of children's developing capacity and eventual respect for their assent or dissent. Recognition of children's developing capabilities has grown such that Canadian policy recently began to explicitly recognize that children's assent and dissent should be determinative in the research consent process as well as in the context of care. Canadian ethics and law have thereby entrenched a patient centered model of care that emphasizes respect for the autonomy of individual patients and the developing autonomy and rights of children in the context of treatment decision-making.

Prima facie, these two perspectives may conflict in their designation of the primary ethical locus of decision-making. According to some interpretations, family-centered care can emphasize the full family unit as the primary focus of ethical consideration, while the children's emerging autonomy/rights perspective clearly puts ultimate authority in the hands of the child. The existence of a conflict may increase risk to patients, physicians, and the institutions in which they work, should physicians fall short of certain duties when giving priority to other

${ }^{*}$ Corresponding author: Randi Zlotnik Shaul JD, LLM, Ph.D, The Hospital fo Sick Children, University of Toronto, Canada, Tel: 416-813-8844; Fax: 416-813 4967; E-mail: randi.zlotnik-shaul@sickkids.ca

Received January 23, 2012; Accepted April 18, 2012; Published April 24, 2012

Citation: Sheahan L, Da Silva, Czoli C, Zlotnik Shaul (2012) A Canadian Perspective on a Child's Consent to Research within a Context of Family-Centered Care: From Incompatibility to Synergy. J Clinic Res Bioeth 3:132. doi:10.4172/21559627.1000132

Copyright: (C) 2012 Sheahan L, et al. This is an open-access article distributed under the terms of the Creative Commons Attribution License, which permits unrestricted use, distribution, and reproduction in any medium, provided the original author and source are credited. 
duties and/or undermine the integrity of clinical care, compromising trust in the physician-patient or physician-family relationship. While one could argue that the different foci of patient/child-centered care and family-centered care do not have normative significance that would justify having a physician deviate from his or her primary fiduciary duty to the patient, the lack of clarity as to how these distinct models are to be integrated in practice, finds the practical application of these two models threatened by inconsistency or destined to only offer purely theoretical value. This paper explores the compatibility of these perspectives and offers a guide as to how these views may be integrated in the context of consent to research.

\section{"Family-Centered Care"}

Family-centered care acknowledges "the importance of family participation in health care" [5]. Although there are many broad definitions and conceptualizations of family-centered care, one of the most well-known models was produced by the Institute for FamilyCentered Care (IFCC). It describes family-centered care as "an approach to the planning, delivery, and evaluation of health care that is grounded in mutually beneficial partnerships among health care providers, patients, and families" [6]. The concept of family-centered care in North America emerged through a strong advocacy movement in the late 1960s led by parents of children with special healthcare needs $[7]^{1}$. The movement argued against the dominant expert model, with parents advocating for more involvement in their child's healthcare and for the healthcare system to recognize the influence of the family on a child's health and wellbeing [7]. Throughout the next 40 years, family-centered care began to influence health policy in the North American pediatric setting. For instance, pediatric hospitals changed their visiting policies from a very restrictive set of visiting hours each day to an open visiting policy allowing parents to stay with their children 24 hours a day [7].

Recent bioethics literature has argued that family-centered care has until now only received a "nominal definition" that does not touch the "real nature" of what is being described [1], but some preliminary features still prove useful. Fostering family-friendly environments, along with acknowledging parental expertise in providing care and encouraging collaboration between parents and the healthcare team emerged as key elements of family-centered care [7]. Indeed, more recent definitions give "all the family members" of a pediatric patient the status of care recipients [8]. This arguably gives all family members a sense of ethical concern that could be translated to the research context with the possible aforementioned implication of multiple family members having a sense of authority in their own right rather than as individual proxies for individual patients.

Contrasted with the medical professional-centered care model, a merging of competing interests into a hybrid "patient- and familycentered care" model, which recognizes the perspectives of both children and their families, has developed [9]. This hybrid "is an approach to the planning, delivery and evaluation of health care that is governed by collaborative partnerships among health care providers, patients and families" [10]. The pediatric hybrid approach of "childand family-centered care" reflects a simultaneous commitment to the focus on patients and recognition of the fact that a pediatric patient is generally embedded in a family unit. It is described as an "equal partnership" between providers and recipients of health care [10]. In the research context, the principles of patient- and familycentered care require designing, conducting and evaluating research in collaboration with parents as well as respecting the diversity and privacy of families $[11]^{2}$. Such collaborative research programs have been widely successful, with programs at schools like the University of Kansas, Stanford University and others proving productive in the domain of evidence-based research [12].

Unfortunately, broad concepts and a lack of empirical evidence make further development and evaluation of family-centered care difficult. Although family-centered care has become widely accepted in children's healthcare, little work has been done to evaluate its effect on child and family outcomes $[8,13]$. While this led some to suggest more research is needed to ensure family-centered care is "being properly implemented", others have argued it is not obvious that familycentered care is "intrinsically good and therefore worthwhile pursuing and getting right” $[3,8]^{3}$.

One area where effectiveness may be questionable is in relation to the tensions between the interests of children and of the family. As Franck and Callery note, "there may be important differences between the perspectives and objectives of children and of their families...[P]arents may not be best placed to assess symptoms and quality of life from their children's point of view" [13]. Semantically, family-centered care and patient-centered care clearly identify different parties as holding the ultimate position of privilege. Just as there can only be one true centre of a circle, there can only be one ultimate position of privilege. Familycentered care developed due to an understanding that "a child's illness has the ability to impact all aspects of family life" [14]. It does not in any way minimize the fact of the child's illness, nor does it explicitly denigrate their decision-making capability. Placing the family at the semantic 'centre', however, could result in considerations relevant to family members taking priority. So, in relation to paediatric research, family-centered care potentially opens the possibility of research being done on a patient-based primarily on the interests of his or her family, while not being held to a strict standard upholding the individual's interests. This risk is of particular concern in a research setting where the benefits to the patient are often less obvious to define.

A strict model of patient-centered care, however, would view the patient as the primary focus of ethical consideration. Inclusion of the child at each stage of the research process and giving the child ultimate authority to at least decide not to participate in a study would be necessary in this framework. A strict reading of patient-centered care could be taken further such that a capable child could participate in a research program without parental permission.

One may wonder if an increased role for children's decisionmaking is desirable; some parents may wish for their consent to be determinative regardless of a child's viewpoint. Parents often have a greater understanding of a given research program. Perhaps their higher epistemic standing should allow their decisions to be determinative. Simply put, parents know more and 'know better' than their children.

'Likewise, it has elsewhere been suggested that a role of parents in their children's health really only began to emerge in the 1950s and 1960s; Palmer S (1993) Care of sick children by parents: a meaningful role. Journal of Advanced Nursing 18: 185-191.

2Johnson et al. claim to adapt these principles from McGonigel M (1998) Guidelines for Family-Centered Research. ACCH, Washington, DC. In 2009, the Institute for Family-Centred Care suggested four main components of family-centred care are dignity and respect, information sharing, participation and collaboration [1].

${ }^{3}$ In response to [3], Veronica Lambert agrees that a problemization of family-centred care is needed to improve it and suggests that the voice of the child is missing in debate on this issue; Lambert V (2009) Response to Carter, B (2008) Commentary on Shields L, Pratt J, Hunter J (2006) Family centred care: A review of qualitative studies Journal of Clinical Nursing 15, 1317-1323 in Journal of Clinical Nursing 17, 2091-2093. Journal of Clinical Nursing 18: 623-624. 
In addition, parents are held legally responsible for their children. They must provide them with both education and the necessaries of life [15]. It may seem inconsistent to allow children to act in a manner that would undermine parents' ability to provide that which they are statutorily obligated to provide.

Currently, clinicians and researchers accept a kind of ill-defined hybrid model for making decisions in pediatric medicine. A hybrid position does not provide us with adequate answers. The Institute for Patient- and Family-Centered Care's core concepts (dignity and respect, information sharing, participation and collaboration) include both patients and family members at each step of the process, but do not clearly articulate who the ultimate decision-maker should be [16]. Amongst equal partners, it is difficult to find an ultimate decisionmaker. A strict family-centered approach would make the third party permission determinative, but such an approach appears incongruous with our increased recognition of the importance of child's rights and developing capacity, including an explicit recognition that children's assent or dissent could be determinative of their participation in a research study.

Franck and Callery suggest that "the difference between 'childcentered' and 'family-centered' care is one of emphasis: neither term can exclude the other, because child-centered care must take account of the social environment in which children live and FCC must be primarily concerned with the health of children" [13]. Under this rubric, there is no merger or hybridization, only an important relationship between related positions. This may not solve the problem entirely, as where one places his or her primary emphasis can nevertheless still lead to substantial differences. While the hybrid model does encourage one to consider the values underpinning each model, it offers little guidance on how to balance the interests or perspectives of the patient/child with the family and how to balance the range of clinical duties that flow from each model, especially in the context of dispute and/or different between the perspectives of patients (children), legal guardians (families) and/ or physicians about what should be done.

\section{Children's Rights to Consent under the Tri-Council Policy Statement}

The increased importance of the child's rights and child's developing capacity framework for the Canadian pediatric research consent context can be best observed by examining Canada's primary research standards document, the Tri-Council Policy Statement (TCPS) [17].

In the absence of statutes devoted to research ethics or common law standards, guidelines, regulations and policy statements are often the best resources for determining the standard of conduct in a given area. Outside of Quebec, where at least research consent standards are proscribed within the Civil Code, the TCPS is the leading research ethics resource in Canada. Canada's three main research fund-granting agencies, the Canadian Institutes of Health Research, the Natural Sciences and Engineering Research Council of Canada, and the Social Sciences and Humanities Research Council of Canada, originally adopted the TCPS in 1998. The TCPS serves a soft law function in Canadian jurisprudence and helps to establish standard of care for Canadian research.

Under the original TCPS, children were recognized as vulnerable persons [18]. Their participation was contingent on their assent or dissent [19]. While children still needed to reach a certain lower capability threshold in order for their assent or dissent to be relevant (i.e., newborns could not give their assent to research), prima facie, respect for children's assent or dissent was an important component of an ethically permissible research study; it was unclear if it was also necessary. Whether a valid parental consent would lead to research participation in the presence of a patient's dissent was questionable. Even where assent and dissent were seen as determinative, the lack of definition of these terms and the lack of clarity on when one is capable of giving determinative assent or consent were problematic. Accordingly, Christy Simpson recommended expanding the role of the child in decision-making about research, clarifying the language surrounding this role and outlining the respective roles and responsibilities of parents, researchers, and REBs in the decision-making process [19].

Children's roles in the TCPS-mandated consent process changed with the December 2010 adoption of its $2^{\text {nd }} \mathrm{draft}$, also known as the "TCPS 2". Recognition of the fact that consent is an ongoing process now explicitly entails recognition of the developing capacity of children. Where third party proxy consent is initially given, researchers must gain valid consent from someone who either a) reaches the age of consent (in the case of children) or b) acquires or regains capacity (in the case of all incapable individuals, including incapable children) [17]. The TCPS 2 notes that "the determination of capacity to participate in research...is not a static determination" [17].

Under TCPS 2, a child is either capable of consent or of assent/ dissent only. However, the TCPS 2 does suggest individuals with "diminished capacity [may] still be able to decide whether to participate in certain types of research" [17]. One wonders if a developing child may be able to consent to some types of research, even if she/he is only capable of giving assent or dissent elsewhere.

Researchers now have a responsibility to seek a child's assent or dissent: "Where children have not yet attained the capacity to consent for themselves to participate in research, researchers shall seek consent from an authorized third party while ascertaining the child's assent or dissent" [17]. The TCPS remains in an assent-dissent framework for those who are incapable of giving fully valid consent on their own, but the necessity of assent or dissent from a child capable of giving it as a component of a valid consent is now explicit: "While their assent would not be sufficient to permit them to participate in the absence of consent by an authorized third party, their expression of dissent or signs suggesting they do not wish to participate must be respected" [17].

The threshold for when a child's assent or dissent is determinative is difficult to parse. Article 3.10 requires "some ability to understand the significance of the research" [17]. Emphasizing the word 'some' suggests a low standard. If, however, one focuses on 'significance', what one needs to understand may be rather robust; it may approximate an appreciation standard. Clinical assent, by contrast, only requires understanding what is being proposed, not appreciating it $[20]^{4}$.

In either case, the explicit recognition of the importance of a capable child's assent or dissent brings the TCPS closer in line, in spirit if not in consequence (given the potentially different standards), with the Ontario Health Care Consent Act's capacity-based analysis. This consistency is desirable given that it can be difficult to draw a

${ }^{4}$ This distinction is commonly referred to in practice and plays a role in the decisionmaking of the Ontario Consent and Capacity Board. For an example of clinical use of the distinction, see the doctor's notes in MM (Re), 2008 CanLII 7375 (ON CCB). For an example of the Board's direct recognition of the distinction, see CP $(\mathrm{Re})$ 2005 CanLII 57840 (ON CCB) ("Ms. C.P. was currently assenting to the testing, without, in the panel's view, having the ability to appreciate the risk or benefit of the testing.") 
sharp divide between clinical care and clinical research in certain circumstances While the trend in paediatric research practice may reflect the notion that child assent/dissent is required for participation in paediatric research, most regulations make it possible for a child to be in study entirely against their expressed wishes... It is also unique in Western bioethics: "both U[nited] S[tates] and ICH [International Conference on Harmonization of Technical Requirements for Registration of Pharmaceuticals for Human Use] regulations specifically allow for a child's participation in a study, against their [meaning the child's] wishes, if it provides them some benefit (which is related to their health). The E[uropean] U[nion], on the other hand, requires only that the dissent be 'considered'. Thus, all three regulations make it possible for a child to be in a study against their wishes" [21].

\section{Seeming Incompatibility?}

The trends in pediatric bioethics of family-centered care and recognition of emerging autonomy and child rights focus on two different values and can lead to different results in a given decisionmaking process. It has been argued that the ethical underpinnings of family-centered care are insufficiently grounded; consequently, the model has failed and "it is ethically untenable to continue to apply it when caring for children and their families" [1]. The basic underlying (pragmatic) argument for its value nonetheless appears to be rooted in the simple suggestion that a child is generally speaking embedded in a family that will have the best sense of what is in the child's best interests ${ }^{5}$. It is possible that family-centered care developed on the basis of, and in conjunction with, recognition of the importance of the value of beneficence. Increased recognition of children's rights and the wider patient-/child-centered care model, by contrast, partially developed as increased respect for children's autonomy.

While a hybrid approach to paediatric research most often result in acceptable outcomes in terms of patient and family interests, it nonetheless fails to give patients and families a clear and coherent understanding of their roles and responsibilities. Researchers thus require a clear model for obtaining consent in paediatric research. The model needs to be broadly applicable, and based around clearly delineated values and principles which clarify the relative weights of potentially conflicting values. An example would be where parental autonomy comes into conflict with the emerging autonomy of an individual child.

According to Richard Miller, the distinctive feature of the pediatric model of medical ethics is that "the norm of beneficence has general priority to the norm of respect for autonomy" [22]. Prioritizing beneficence essentially means acting in a child's 'best interests'. The beneficence standard has a number of unique components in pediatrics. Most importantly, a child's 'best interests' are intimately tied to his or her social unit, and we must therefore recognize the importance of the family unit. This value or right is not synonymous with the value or right of patient autonomy, and is therefore accorded a different status in the decision-making process.

The importance of the family unit, as is enshrined in familycentered care, thus elevates the idea of parental autonomy, where parents may be considered the ultimate locus of decision making. The obligation to recognize the significance of parental autonomy is

${ }^{5}$ Of course, critics also argue against this point. Amongst other criticisms, for in stance, Lauren J. Breen suggests the movement is based on a neoliberal, idealized understanding of the family; Breen $L$ (2009) Early childhood service delivery for families living with childhood disability: disabling families through problematic implicit ideology. Australasian Journal of Early Childhood 34: 14-21. contingent on parents fulfilling their obligations toward children. Where parents fail to act in the best interests of their children, outsiders may justifiably intervene in a family's domestic affairs to ensure that health care decisions are made in accordance with the child's best interests and where children may be in need of protection. The focus of ultimate ethical consideration may be the child in a beneficence model, but a substitute decision-maker, often a family member, is the ultimate ethical decision-maker. While consideration of the interests of the child is to be the focus of the family's decision-making rights, care decisions are centered on what the parents decide.

The first question for the researcher in pediatrics, therefore, becomes can this child give autonomous consent to participate in this project? For the purposes of consent to research in pediatrics, autonomy can be seen as having two essential components: decision-making autonomy and executional autonomy. Decision-making autonomy refers to the ability and freedom to make decisions without external coercion, and executional autonomy refers to the ability one has to implement decisions made [23]. In both research and treatment models for adults, decision-making autonomy tends to 'trump' all other relevant values.

The TCPS 2 marks an important moment in which children's autonomy is increasingly recognized. Children develop capacity for self-determination in decision-making as they mature. This creates an obligation to respect both the developing autonomy of young people, and their full capacity and independence when it is reached. Pediatric patients, therefore, should gradually accrue the rights accorded to adults in light of their full capacity for self-determination. In the research context they develop a right to dissent even prior to the full right to consent accorded to capable persons in the clinical context. Unlike in the previous TCPS, this dissent is now clearly determinative.

Different foci of ethical consideration (family interests vs. children's rights) can lead to different conclusions in a given decision-making process. It is not enough to say that which is good for a patient is good for his family and vice versa. Parents and children do not always agree about what is best for a child.

\section{Privacy: A Third Concern?}

A further logistical problem arises when initially gaining consent: who does one approach first and what can one share with the other party? Respect for autonomy entails respect for children's decisions as to what medical information is shared with others. Under Canadian law, capable youths have a right to have their information kept private [24]. For the competent child who is thinking about research, approaching parents about the research may result in a lack of respect for this position. Approaching parents with information about a study may violate privacy if inclusion/exclusion criteria are included in the discussion. Study information provision would thereby give away medical information children may want to keep private. Approaching parents about the theoretical idea of a study only, however, is less than adequate information provision for making a third party proxy decision.

On the other hand, asking children for permission may require explaining the research purpose to the children prior to telling their family about it. Family-centered care demands the inclusion of parents in the decision-making process. It is understandable that recruiters may feel uneasy about discussing research with children without parental presence. In order to ascertain permission to share information, however, such a discussion will need to take place. Discussing consent to disclosure of information without knowing what 
the disclosure is all about runs into the same theoretical problems as the theoretical discussion of a study mentioned above. Operationalizing both autonomy and family-centered care will accordingly require consideration of how to work around related privacy concerns.

\section{An Analogous Case?}

TCPS 2 does provide another example of synergy between group interests and individual interests within a TCPS 2 research context. The TCPS 2 devotes a chapter on how to promote such synergy in Aboriginal communities. Chapter 9 of the TCPS 2 is identified by the Tri-Council funding agencies as "a significantly changed chapter" [25]. Drawing on public consultations, Chapter 9 , serves as a framework for the ethical conduct of research involving Aboriginal peoples premised on respectful relationships and encouraging collaboration between researchers and research participants, and community engagement [25]. Community leaders must be consulted before research is conducted in Aboriginal communities, though the leaders do not necessarily recruit individuals for the research program.

The example of Aboriginal communities has many parallels with the concept of consent in the paediatric context, and can provide instruction on how to integrate family-centered care with the patient centered care in a paediatric research setting. Just as community for this group has a heightened significance around consent to research, family should be recognized as serving a similar role for children. The family member's permission is important, but so too is the individual patient's decision not to participate in something of which the parent approves. Additionally, just as article 9.6 states that there are diverse interests in a community, such that a certain leader's decision is not dispositive [17], so too is there a wide breadth of interests in a family, such that a parent's view is important, and whereby other family interests remain relevant. This is not an instance of individual consent waiver, but of an acknowledgment that cultural sensitivity is a prerequisite for even seeking it. Relatedly, one may wish to acknowledge the importance of a family context when seeking and examining the legitimacy of consent.

Community engagement is one aspect of Aboriginal research context that demonstrates that model's ability to meet the demands of both individuals and the groups of which they are members. It "is a process that establishes interaction between a researcher or research team, and the Aboriginal community relevant to the research project" [17]. Article 9.12 states that it is a collaborative process where even the nature of engagement is determined through collaboration and Article 2.9 states that the "nature and extent of community engagement in a project shall be determined jointly by the researcher and the relevant community, and shall be appropriate to community characteristics and the nature of the research" [17]. Community engagement is also highly contextual: "[ $t$ ] he engagement may take many forms including review and approval from formal leadership to conduct research in the community, joint planning with a responsible agency, commitment to a partnership formalized in a research agreement, or dialogue with an advisory group expert in the customs governing the knowledge being sought" [17]. All research, however, must be relevant and respond to the community's needs and priorities: "The research should benefit the participating community... as well as extend the boundaries of knowledge" [17]. Combining Articles 9.11 and 9.16, one sees that operationalizing a research agreement between a community and researcher, as required by the TCPS 2 , without violating privacy may be difficult, but is necessary: "Researchers shall not disclose personal information to community partners without the participant's consent" [17]. While the demands in the paediatric research context differ, one may likewise wish to examine ways to meet both individual (patient) and community (family) demands in that context.

Synergy between community and individual interests (and the supremacy of the privacy of the latter) is now recommended by the TCPS 2. We propose a similar synergy below. It does not incorporate the Aboriginal model in toto, but does adopt the Aboriginal model's reflection of the fact that integrating group and individual research in the research context is a largely collaborative and contextual undertaking. One must respect both the group and the individual, but how to do so may change in different circumstances.

\section{A Proposed Model for Operationalizing These Values}

Given the seeming incompatibility of these trends, one is left wondering which should take precedence. Given the value of autonomy which permeates consent discussion, the TCPS 2's recognition of children's rights to assent/dissent is to be applauded. The pediatric patient must be the centre of any decision-making discussion concerning health services provision for that child. Operationalizing this primary right, however, requires a recognition of the fact that many children are embedded in a family relationship, which is deeply tied to their ability to provide consent and their interests. Beyond the logistical support that families must provide to children in research studies (i.e. arranging transportation to the hospital for children living at home), families also provide the context in which many children's identities are formed and decision-making capabilities are realized. Many children must be able to speak with their parents in order to gain full understanding of their decision. Many also respect their parents' opinions, even if they ultimately do not agree with them. Increased recognition of children's rights must be accompanied by recognition of the family-centered nature of their decision-making. However, presuming what is good for the family is good for the patient is insufficient. Ultimately, a patient's rights must triumph. Those rights, however, are deeply influenced by the family context.

That family-centered care is closely related to patient-centered care was clear even before the development of the hybrid position. Prior to the recognition that patients too must be partners in the clinical process, hybrid position and family-centered pioneers Johnson et al. were aware of the importance of children's rights in the research consent context. In 1992, they argued that guidelines for research on children in a psychosocial context, including 1) seeking consent from parents and assent from children and 2) no participation requirement without assent, should apply in other contexts as well [11]. Both parents and children were to be told that their participation was voluntary [11]. How this position was to be reconciled with the family, as the primary focus of ethical consideration, however, was left undeveloped.

In practice, the hybrid model of family and patient centered care often functions reasonably well despite its potential conflicts, Nevertheless, the parameters of this model have not yet been fully developed. The American Association of Paediatrics Committee on Bioethics identified many of the pertinent issues in their review in 1995 [26], but stopped short of constructing an applicable model for consent in paediatric research. A delineation of the underlying values that are relevant in considering consent in paediatric research is required, along with a clearly defined model for applying those principles in research practice. In order to fully operationalize these trends in concordance, we recommend the following principles:

i. The priority of research ethics remains an obligation to protect the potential research subject from undue harm. This 
responsibility lies with the researchers themselves, with the $\mathrm{REB}$, and with parents or guardians who are involved in the decision-making process.

ii. With incapable children, beneficence has presumed priority over other values; including autonomy per se. Respect for a child's individual autonomy can be seen as one part of understanding and acting in accordance with beneficence or best interests.

iii. The relative weight of respect for individual autonomy in determining best interests or beneficence increases as the child develops decision-making capacity. Along with accompanying executional autonomy or independence, this eventually leads to endorsement of a fully adult model, where it is presumed that the capable individual's choices in self determination will be the best way to pursue that individual's best interests. Decision-making autonomy alone does not accord a pediatric patient complete independence or endorsement of the capable adult model, as executional autonomy is also required. Both components of autonomy are context specific, depending on the type of research proposed. The consent process for each study should be reviewed with this in mind.

iv. Family as a social unit in pediatric medicine holds a special place. This is because of the necessary dependence of a child on their family unit, and because of a family's increased relative value to the child's best interests. These relational aspects create special obligations on behalf of parents toward their children. They also necessitate a greater obligation to respect the role of family in the context of pediatric research. Specifics for consideration in pediatric research include:

a. Family discordance can be understood as a harm that holds relatively more weight in pediatric research than in adult research.

b. The social value of parental values has comparably more weight in the pediatric environment than in the adult environment.

c. Participation of a dependent child in research may result in specific responsibilities for a family, and as such will result in obligations on behalf of the family to their child. Participation may also result in potential harms to the guardian or family. The creation of these obligations and harms holds moral weight, and they are therefore important factors to consider in ethical deliberations regarding participation in research. In the case of a child who possesses decision-making autonomy, but not independence (as defined below), this should allow for a permission step to be included in the model, where the guardian accepts these burdens or potential harms. This should ideally be done in the presence of the capable child, providing an opportunity for them to exert independence or executional autonomy.

v. When in doubt, err on the side of non-participation. There are variable potential 'benefits' to participating in research for the child subject, which alter the harm-benefit ratio in accordance with both the nature of the research being conducted and the patient's specific context [27].

vi. Where pediatric subjects are unable to consent for themselves, respect for their developing autonomy requires us to provide information relevant to their developmental level. Where a child is able to understand, his or her assent should be necessary to enrol in the research project. Unlike in treatment decisions, the benefits of research are not weighty enough to override dissent from a child who understands what is being proposed.

vii. Variables for consideration in the harm benefit analysis for pediatric subjects therefore should include:

a. Nature of the research and its likely harms and benefits

b. Level of risk

c. Potential subjects' capacity/competence to make their own decision in regards to this specific project

d. Social or cultural components in determining benefits or 'best interests', including needs, values, priorities, and social expectations.

e. Parent's current role and position in relation to the child, including action on behalf of their child's interests, and potential conflict of interests. This is relevant in light of the social value of parental decision-making, and in light of the extra obligations incurred by guardian and family by participating in research.

Using these principles, the following model is proposed:

KEY:

\section{'Independent' is:}

1. As determined by law (e.g. by the age of majority in that province, where pregnant or have their own children/family, or where they are completely outside of parental control)

2. Where the potential subject has full executional autonomy in the specific area proposed for investigation (i.e. able to act on decisions and family not affected)

3. Where the claims a parent/guardian has to decision-making authority are justifiably forfeited by their failure to execute their duties toward the child (i.e. basic interest protection)

'Proxy Consent' refers to authorization by a capable and legally responsible third party for a subject to participate in research. It should remain distinct from informed consent obtained from an individual

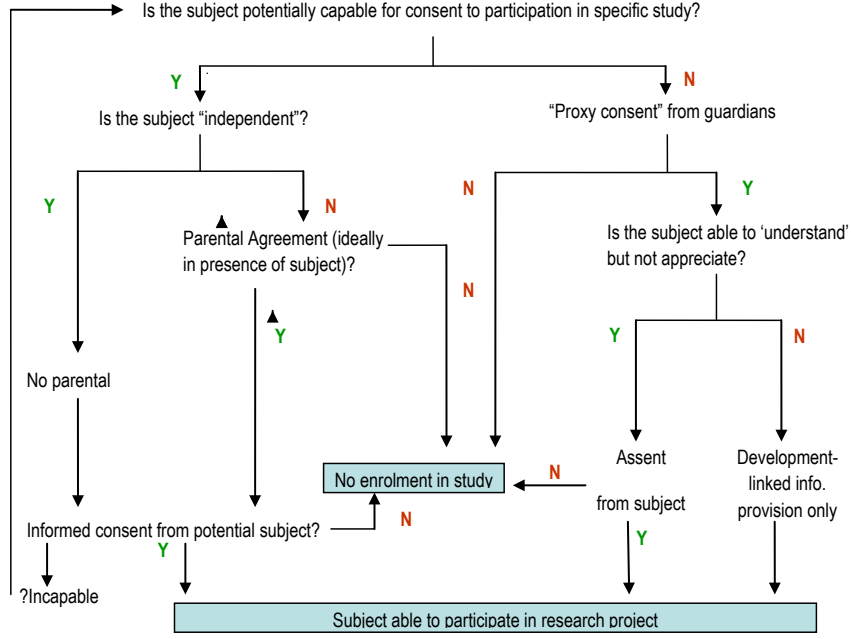

Figure 1: Pediatric Consent Schema. 
Citation: Sheahan L, Da Silva, Czoli C, Zlotnik Shaul (2012) A Canadian Perspective on a Child's Consent to Research within a Context of FamilyCentered Care: From Incompatibility to Synergy. J Clinic Res Bioeth 3:132. doi:10.4172/2155-9627.1000132

subject, but still considered a valid authorization for participation in research.

'Assent' involves agreement to participate by an incapable subject, where the subject is able to understand but not fully appreciate the decision. It recognizes the developing capacity for decision-making, and thus allows children to have some authority over their participation in research. Valid assent requires the provision of information in terms understandable by the potential subject-participant.

\section{Conclusion}

Simultaneous recognition of individual and group interests is an important component of pediatric research. It helps to promote synergy between two dominant trends in contemporary pediatric research and research ethics: family-centered care and respect for children's rights and emerging autonomy. It thereby helps integrate seemingly incongruous family- and patient/child-centered care models. While the semantics surrounding the former prove problematic insofar as they move the moral locus away from the individual patient (who we argue is the ultimate primary source of ethical consideration), the role of the family in pediatric ethics is important. It is often the backdrop for autonomous decision-making.

The simultaneous recognition of individual and group interests would not be new to Canadian research ethics guidelines. The TCPS 2 already attempts synergy in the case of Aboriginals. We propose an analogous recognition of the competing interests in the pediatric context. As in the Aboriginal case, pediatric research ethics must be collaborative and contextual, as different circumstances will require different results. Our pediatric consent to research schema clearly articulates the important values at stake, and provides a reproducible and transferrable guideline for how to deal with our growing appreciation of issues surrounding consent in paediatric research.

\section{References}

1. Shields $L$ (2011) The Ethics of Family-Centered Care for Hospitalised Children. In: Brykczyńska G, Simons J (eds) Ethical and Philosophical Aspects of Nursing Children and Young People. Wiley-Blackwell, Ames, IA: 144-154.

2. Conway J (2008) Patients and Families. Healthc Exec 23: 60-62.

3. Carter B (2008) Commentary on Shields L, Pratt J \& Hunter J (2006) Family centered care: a review of qualitative studies. J Clin Nurs 17: 2091-2093.

4. Kovacs P, Hayden Bellin M, Fauri D (2006) Family-Centered Care: A Resource for Social Work in End-of-Life and Palliative Care. J Soc Work End Life and Palliat Care 2: 13-27.

5. Williams WG (2006) Advanced Practice Nurses in a Medical Home. J Spec Pediatr Nurs 11: 203-206.

6. http://www.ipfcc.org

7. MacKean G, Thurston W, Scott CM (2005) Bridging the divide between families and health professionals' perspectives on family-centered care. Health Expect 8: $74-85$

8. Shields L, Pratt J, Hunter J (2006) Family centered care: a review of qualitative studies. J Clin Nurs 15: 1317-1323.

9. Institute for Family-Centered Care (2008) Advancing the Practice of Patientand Family-Centered Care: How to Get Started. Institute for Family-Centered Care, Bethesda, MD.

10. Sodomka P (2006) Engaging Patients \& Families: A High Leverage Tool for Health Care Leaders. Hospitals and Health Network: 28-29.

11. Johnson B, Seale Jeppson E, Redburn L (1992) Caring for Children and Families: Guidelines for Hospitals. Association for the Care of Children's Health, Bethesda, MD.

12. Johnson B (2008) Partnering with Patients and Families to Design a Patient- and Family-Centered Health Care System: Recommendations and Promising Practices. Institute for Family-Centered Care, Bethesda, MD.

13. Franck LS, Callery $P$ (2004) Re-thinking family-centered care across the continuum of children's healthcare. Child Care Health Dev 30: 265-277.

14. Locsin R (2003) Culture Perspectives. Holist Nurs Pract 17: ix-xii.

15. Criminal Code, R.S.C. 1985, c. C-46, Section 215 rev 1991 (cited 27 March 2008) Available from: http://www.canlii.org/ca/sta/c-46/sec215.html.

16. http://www.ipfcc.org/pdf/CoreConcepts.pdf.

17. Canadian Institutes of Health Research, Natural Sciences and Engineering Research Council of Canada, and Social Sciences and Humanities Research Council of Canada, Tri-Council Policy Statement: Ethical Conduct for Research Involving Humans (TCPS 2), December 2010.

18. Canadian Institutes of Health Research, Natural Sciences and Engineering Research Council of Canada, and Social Sciences and Humanities Research Council of Canada, Tri-Council Policy Statement: Ethical Conduct for Research Involving Humans, 1998 (with 2000, 2002, 2005 amendments).

19. Simpson C (2003) Children and Research Participation: Who makes what decisions. Health Law Rev 11: 20-29.

20. Diekema DS, Mercurio MR, Adam MB (2011) Clinical Ethics in Pediatrics: A Case-Based Textbook. Cambridge University Press, New York: 2-3.

21. Blake V, Joffe S, Kodish E (2011) Harmonization of Ethics Policies in Pediatric Research. J Law Med Ethics 39: 70-78.

22. Miller R (2003) Children, Ethics \& Modern Medicine. Indiana University Press, Indiana.

23. Collopy BJ (1988) Autonomy and long term care: some crucial distinctions Gerontologist 28: 10-17.

24. Personal Health Information Protection Act, 2004, SO 2004, c 3, Sch A s. 23 of PHIPA.

25. Interagency Advisory Panel on Research Ethics, Table of Concordance 1st Ed. 1998 to 2nd Ed. 2010.

26. REF Committee on Bioethics (1995) Informed consent, Parental Permission and Assent in Paediatric Practice. Committee on Bioethics, American Academy of Pediatrics. Paediatrics 95: 314-317.

27. Miller PB, Kenny NP (2002) Walking the Moral Tightrope: Respecting and Protecting Children in Health Related Research. Camb Q Healthc Ethics 11 217-229. 